\title{
Relation between Internalized Stigma and its correlates among Psychiatric Inpatients in Minia Governorate
}

\author{
Tahany Shaaban Mohammed ${ }^{1}$, Ikram Ibraheem Mohammed ${ }^{2}$, and Sabah Saleh Hassan ${ }^{3}$
}

1. (Assistant lecturer of psychiatric and Mental Health Nursing, Faculty of Nursing, Minia University)

2. (Professor of Psychiatric and Mental Health Nursing, Faculty of Nursing, Assuit University)

3. (Assistant Professor of Psychiatric and Mental Health Nursing, Faculty of Nursing, Minia University)

\begin{abstract}
Background: People experiencing or perceived to have a mental illness often subject to stigma from many sources which can be automatically internalized and result in internalized stigma. Aim: This study aimed at assessing the levels of internalized stigma and explores relation between demographic, clinical data, and internalized stigma among psychiatric inpatients in Minia governorate. Research Design: A descriptive correlational research design was used in this study. Study subjects and setting: 50 psychiatric inpatients at Minia Hospital for Mental Health and Addiction Treatment in New Minia City were included in the study. Tools: Socio-demographic and clinical data questionnaire and Internalized Stigma of Mental Illness Scale were used. Results: More than half $(60 \%)$ of the studied patients were males, near to one third $(30 \%)$ had schizophrenia, less than two thirds $(60 \%)$ of them had a moderate level of internalized stigma, while $26 \%$ of them had high level of internalized stigma and only $14 \%$ of them had low level of internalized stigma. Conclusion: There were no statistically significant differences between internalized stigma levels and all sociodemographic and clinical data of the patients except for occupation and duration of hospitalization. Recommendations: Designing and implementing psycho-educational programs for psychiatric mentally ill patients to decrease internalized stigma are needed.
\end{abstract}

Keywords: Clinical data, Internalized stigma, Psychiatric patients, Sociodemographic data.

\section{Introduction:}

Psychological disorders are often used interchangeably with the terms of mental disorders, psychiatric disorders, or mental illness, the "formal" term is mental disorders which was defined in the last edition of the American Psychiatric Association's diagnostic manual (the DSM-5) as: "a syndrome that is characterized by clinically significant disturbances in an individual's cognition, emotion regulation or behavior that reflect a dysfunction in the psychological, biological or developmental process underlying mental functioning (American Psychiatric Association APA, 2013). Mental illnesses are prevalent worldwide and in Egypt. The global prevalence of common mental disorders is approximately 1 in 5 adults (17.6\%) (Steel et al., 2014). A recent World Health Organization (WHO) meta-analysis estimated that the prevalence of mental disorders was $22.1 \%$ in emergency settings (Charlson et al., 2019). In Egypt, the National Survey of Mental Disorders estimated overall prevalence as $16.93 \%$ of the studied adult population (Ebrahim et al., 2020).

Unfortunately, it is observed that once individuals are referred to a psychiatrist and are diagnosed with a mental disorder, they feel stigmatized and according to prevailing theories, some of these stigmatized individuals internalize and apply these negative attitudes and stereotypes to themselves, resulting in what has been defined as "self-stigma (Schwarzbold et al., 2021). According to Corrigan \& Rao (2012), self-stigma develops in progressive stages: Individuals become aware of public stigma, agree with negative stereotypes, and apply these stereotypes to themselves resulting in poorer self-esteem and self-efficacy (Hofer et al., 2019).

Internalized stigma, or self-stigma, has been defined as "shame, evaluative thoughts, and fear of enacted stigma that results from individuals' identification with a stigmatized group" (Olçun \& Altun, 2017 and Yılmaz \& Okanlı, 2015). Also, Corrigan \& Rao. (2012) added that, the process of internalized stigma includes the repeated occurrence of negative emotions and thoughts about the stigma and the fact that such thoughts come automatically and involuntarily. In this respect, Sen. (2018) clarified that, stigma arises when insufficient or incomplete knowledge supports negative stereotypes regarding a marginalized population - facilitating discrimination and exclusion. For instance, stigma can be derived from the belief that people with mental illness are responsible for their illness, incompetent, violent, and weak in character and therefore should be socially restricted (Eksteen et al., 2017).

Furthermore, self-stigma has been associated with poorer treatment adherence (Kamaradova et al., 2016 and Yilmaz \& Okanl,, 2015) and with negative outcomes, including reductions in self-esteem (Hofer et al., 2016 and Picco et al., 2016), hope (Berry \& Greenwood, 2018), quality of life (Lien et al., 2018 and Picco et al., 2016). Internalized stigma is prevalent among individuals with serious mental illness and can have a negative impact on selfconcept, social relationships, community involvement, psychiatric health, and well-being and may impede the recovery process for individuals with mental illness as concluded by Drapalski et al., (2013).

To date, the correlation between internalized stigma and sociodemographic as well as clinical variables remains unclear, and there are few studies exploring such correlations, especially in developing countries. Understanding the internalized stigma and how it correlates to sociodemographic (age, gender, education, etc.), and clinical health related factors (diagnosis, disease duration, etc.) may help in informing interventions to reduce it among psychiatric patients. (Szcześniak et al., 2018 and Howland et al., 2016). 
Regarding sociodemographic variables, the lack of consistency across disparate studies indicates that mentally ill people with a wide range of characteristics are susceptible to internalized stigma. The association of gender, education, and other demographic variables with the ISMI scale scores were not reported in the original English version. Also, in the Japanese version, the study concluded no significant differences in the association between the total ISMI scale score and demographic variables (Tanabe et al., 2016).

Concerning clinical variables, some studies confirm an association between the number of hospital admissions and internalized stigma (Vrbova et al., 2016), whereas others contradict this finding and show no such relation (Holubova et al., 2016). As regard to the duration of the disease the same author documented that the degree of internalized stigma is lower in patients with unipolar affective disorder compared with patients with psychotic disorders (PDs). On the contrary, Kamaradova et al., 2016 showed that the duration of the disease has't not been confirmed to be linked with internalized stigma and the influence of the type of clinical diagnosis is also unestablished Holubova et al., 2016.

\section{Significance of the study}

Several studies in different countries showed that around 80 to 90 percent of patients with mental illness may experience stigma and discrimination; these rates of internalized stigma differ across samples from moderate to severe (Tesfaye et al., 2020). In a study conducted in "Singapore" among psychiatric outpatients, there were, $43.6 \%$ of patients experienced moderate to a high level of internalized stigma (Picco et al., 2016) and in a Chinese study, it was reported that $38.3 \%$ of Hong Kong and $49.5 \%$ of Guangzhou patients were having self-stigma (Young \& Ng., 2016). Furthermore, in a descriptive study conducted in Minia governorate, Upper Egypt by (Omer et al., 2016), the results revealed that more than half $(53.6 \%)$ of the studied patients had a higher level of internalized stigma.

\section{Aim of the study}

This study aimed to:

1- Assess levels of internalized stigma among psychiatric inpatients at Minia governorate.

2- Investigate relation between sociodemographic, clinical data, and internalized stigma among psychiatric inpatients in Minia governorate.

\section{Subjects and Methods \\ Research design:}

A descriptive correlational research design was utilized in this study.

\section{Setting}

This study was conducted at the New Minia Mental Health and Addiction Treatment Hospital in New Minia City which is affiliated to the Ministry of Health. The hospital involves two floors; the outpatient clinics, the pharmacy and the female inpatient unit are on the first floor. The second floor includes the administration office, the department of substance use treatment, male psychiatric inpatient units, and the nursing office. The capacity of this hospital is 53 beds for both sexes which serves the whole Minia governorate.

\section{Subjects:}

A convenience sample of 50 psychiatric inpatients was included in the study.

\section{Inclusion Criteria:}

- Both genders.

- Patients' age ranges from 18 to 55 years.

- Patients who can communicate and interact effectively.

\section{Exclusion criteria}

- Mental retardation (intellectual disability) .

- Comorbid diagnosis of substance dependence.

- Acute stage of psychosis.

Tools of Data Collection:

Two tools were utilized in this study:

\section{Tool (1) Sociodemographic and clinical data questionnaire:}

It was developed by the researcher to assess patients' demographic and clinical data which cover the following items: age, gender, residence, educational level, marital status, occupation, diagnosis, duration of illness, as well as date and type of admission.

\section{Tool (2) Internalized Stigma of Mental Illness Scale (ISMIS):}

This scale was developed by Ritsher et al., (2003) which includes 29 items that asses internalized stigma. It consists of five subscales that include: alienation (items 1, 5, 8, 16, 17 and 21), stereotype endorsement (items 2, 6, 10, 18, 19, 23 and 29), discrimination experience (items 3, 15, 22, 25 and 28), social withdrawal (items 4, 9, 11, 12, 13 and 20) and stigma resistance (items 7, 14, 24, 26 and 27). The items are rated by using a 4-point Likert type scale ranged from ( $1=$ strongly disagree to $4=$ strongly agree). The items of the "stigma resistance" subscale are scored in reverse. The total ISMIS score was obtained by adding the scores of five subscales ranging from 29 to 116 points. The higher scores in the ISMI mean that the internalized stigmatization of the person is more severe in the negative sense and the lower scores mean the higher stigma resistance.

Validity: The content validity of the study used scale was tested by five psychiatric and mental health nursing experts. Based on the experts' comments and recommendations, modifications were done.

Reliability: The reliability of the tools was done by the statistician and revised by the supervisors. The internal consistency of the study scale was calculated using Cronbach's alpha coefficients test, it was 0.92 which meant that it was highly reliable.

\section{Pilot study}

A pilot study (10\%) of the total number that equal to 5 patients of the studied patients was performed to test the research process and determine the feasibility and reliability of the tools used in the study. It also helped in the assessment of the necessary time to fill the tools.

\section{Field work}

The purpose of the study was explained by the researcher through direct personal communication with the 
studied patients for getting their approval and voluntary participation. The researcher went to the hospital two days/ week (Saturday, and Monday,) from 9 to 1 p.m.

\section{Administrative Design:}

An official permission was approved from the director of the New Minia hospital for Mental Health and Addiction Treatment at Minia city to conduct the study. Oral and written agreements for patients' participation in the study were obtained from the studied patients themselves and the patient ethical committee in the hospital.

\section{Ethical Considerations:}

A written initial approval obtained from the Research Ethical Committee of the Faculty of Nursing, Minia University, the study follows common ethical participation in clinical research, there is no risk for study subjects during application of this research, and privacy was provided during data collection. Anonymity and confidentiality were assured through coding the data.

\section{Statistical Analysis}

Recorded data were analyzed using the statistical package for social sciences; version 26.0 Quantitative data were expressed as mean \pm standard deviation (SD). Qualitative data were expressed as frequency and percentage. Also, Pearson correlation was used.

\section{Results}

Table (1): Frequency distribution of the studied psychiatric patients according to their sociodemographic data $(\mathrm{N}=50)$.

\begin{tabular}{|c|c|c|}
\hline Sociodemographic data & No $=50$ & $\%$ \\
\hline $\begin{array}{cl}\text { Marital status } \\
\bullet & \text { Single } \\
\bullet & \text { Married } \\
\bullet & \text { Divorced } \\
\bullet & \text { Widow }\end{array}$ & $\begin{array}{l}\mathbf{2 0} \\
19 \\
10 \\
1\end{array}$ & $\begin{array}{l}\mathbf{4 0} \\
38 \\
20 \\
2\end{array}$ \\
\hline $\begin{array}{ll}\text { Educational level } \\
\text { - } & \text { Illiterate } \\
\text { - } & \text { Read and write. } \\
\text { - } & \text { Primary } \\
\text { - } & \text { Prep } \\
\text { - } & \text { Secondary } \\
& \text { University \& above }\end{array}$ & $\begin{array}{l}7 \\
7 \\
2 \\
\mathbf{1 9} \\
4 \\
11\end{array}$ & $\begin{array}{l}14 \\
14 \\
4 \\
\mathbf{3 8} \\
8 \\
22\end{array}$ \\
\hline \begin{tabular}{cc}
\multicolumn{2}{l}{ Residence } \\
$\qquad \quad$ Rural \\
$\bullet \quad$ Urban
\end{tabular} & $\begin{array}{l}\mathbf{3 8} \\
12\end{array}$ & $\begin{array}{l}76 \\
24\end{array}$ \\
\hline
\end{tabular}

Table (1) shows that, $60 \%$ of patients were males, 38\% of them were in the age group "more than 38 years old", had preparatory school and they were unemployed/housewife. Also, $40 \%$ were single and the majority of them live in rural areas (76\%).

Table (2): Frequency distribution of the studied psychiatric patients according to their clinical data $(\mathrm{N}=50)$.

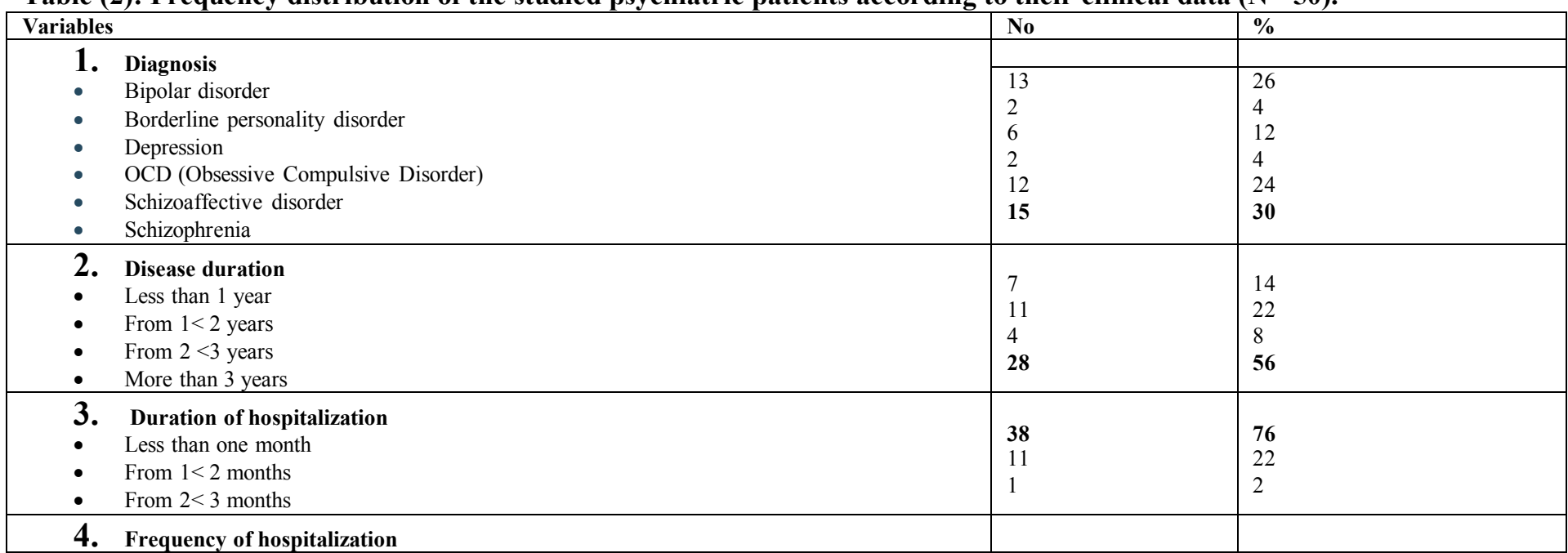




\begin{tabular}{|c|c|c|}
\hline Variables & No & $\%$ \\
\hline $\begin{array}{ll}\text { 5. } & \text { Mode of transmission } \\
-\quad & \text { Voluntary } \\
- & \text { Involuntary }\end{array}$ & $\begin{array}{l}31 \\
19\end{array}$ & $\begin{array}{l}\mathbf{6 2} \\
38\end{array}$ \\
\hline
\end{tabular}

Table (2) reflects that $30 \%$ of patients had schizophrenia, more than half $(56 \%)$ of them had the disease for more than three years. Meanwhile about three quarters of them $(76 \%)$ had been hospitalized less than one month. Regarding mode of admission, it was found that $62 \%$ of them were admitted voluntarily.

Table (3): Frequency distribution of the studied psychiatric patients' responses to internalized stigma (ISMI) at Pretest (n= 50).

Items

Alienation

1. I feel out of place in the world because I have a mental illness.

2. I am embarrassed or ashamed that I have a mental illness.

3. I feel inferior to others who don't have a mental illness.

4. I am disappointed in myself for having a mental illness.

5. Having a mental illness has spoiled my life.

6. People without mental illness could not possibly understand me.

Mean $\pm \mathrm{SD}=\mathbf{1 6 . 7} \pm \mathbf{5 . 4}$

Stereotype endorsement

7. Mentally ill people tend to be violent.

8. Mentally ill people shouldn't get married.

9. People with mental illness cannot live a good, rewarding life.

10. People can tell that I have a mental illness by the way I look.

11. Because I have a mental illness, I need others to make most decisions for me.

12. I can't contribute anything to society because I have a mental illness.

13. Stereotypes about the mentally ill apply to me.

Mean $\pm \mathrm{SD}=16.3 \pm 4.4$

Discrimination experience

14. People discriminate against me because I have a mental illness.

15. People often patronize me, or treat me like a child, just because I have a mental illness.

16. People ignore me or take me less seriously just because I have a mental illness.

17. Nobody would be interested in getting close to me because I have a mental illness.

18. Others think that I can't achieve much in life because I have a mental illness.

\section{Mean $\pm \mathrm{SD}=14 \pm 5$}

\section{Social withdrawal}

19. I avoid getting close to people who don't have a mental illness to avoid rejection.

20. I do not socialize as much as I used to because my mental illness might make me look or behave "weird."

21. I do not talk about myself much because I don't want to burden others with my mental illness.

22. Negative stereotypes about mental illness keep me isolated from the "normal" world.

23. Being around people who do not have a mental illness makes me feel out of place or inadequate

24. I stay away from social situations to protect my family or friends from embarrassment.

Mean $\pm \mathrm{SD}=17.2 \pm 5$

Stigma resistance

25. People with mental illness make important contributions to society.

26. I feel comfortable being seen in public with an obviously mentally ill person.

27. Living with mental illness has made me a tough survivor.

28. In general, I am able to live my life the way I want to.

29. I can have a good, fulfilling life, despite my mental illness.

Mean $\pm \mathrm{SD}=11 \pm 3.2$

Total $\quad$ Mean $\pm \mathrm{SD}=\mathbf{7 6 . 4} \pm 16.6$

Notes: ISMS $=$ Internalized Stigma of Mental Illness Scale.

Table (3) demonstrates that, (66\%) of patients are strongly agree that "they are disappointed in themselves for having mental illness", more than half (54\%) were strongly disagreed that they can't contribute anything to society because they have a mental illness, while less than half $(40 \%, 34 \%, 34$ and $34 \%)$ were strongly agreed that mentally ill people tend to be violent, shouldn't get married, people can tell that they have a mental illness by the way they look and stereotypes about the mentally ill apply to them respectively.

The same table illustrates that more than half (56\%) of them were strongly agreed that people ignore them or take them less seriously just because they have a mental illness, more than two thirds $62 \%$ were strongly agreed that negative stereotypes about mental illness keep them isolated from the "normal" world. Meanwhile, nearly two thirds (62\%, and $60 \%)$ were strongly disagreed that they could live their life the way they want to and people with mental illness make important contributions to society. 


\section{levels of stigma}

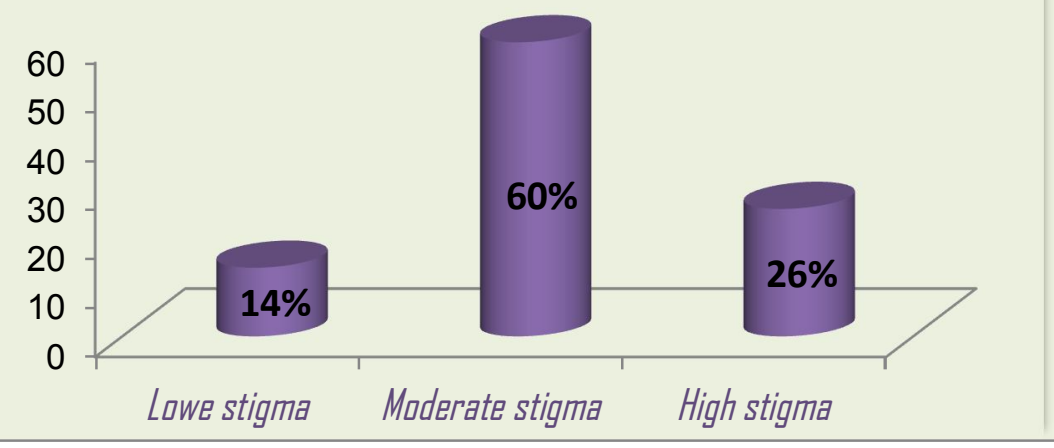

Figure (1): Frequency distribution of internalized stigma levels among the studied psychiatric patients $(\mathrm{N}=50)$.

Figure (1): clarifies that, (60\%) of the patients had a moderate level of internalized stigma, about one quarter (26\%) of them had a high level of internalized stigma and 14\% have a low level of internalized stigma.

Table (4): Frequency distributions of ISMI subscales levels among the studied psychiatric patients $(\mathrm{N}=50)$.

\begin{tabular}{|l|l|}
\hline Subscale & Mean \pm SD \\
\hline Alienation & $16.7 \pm 5.4$ \\
\hline Stereotyping & $17.3 \pm 4.4$ \\
\hline Discrimination & $14 \pm 5$ \\
\hline Social withdrawal & $17.2 \pm 5$ \\
\hline Stigma resistance & $11 \pm 3.2$ \\
\hline
\end{tabular}

Table (4): clarifies that, according to frequency distributions of ISMI subscales' levels, the highest mean score was related to stereotyping and social withdrawal subscales followed by alienation subscale.

Table (5): Relationship between the studied psychiatric patients' levels of internalized stigma and their scio-demographic data

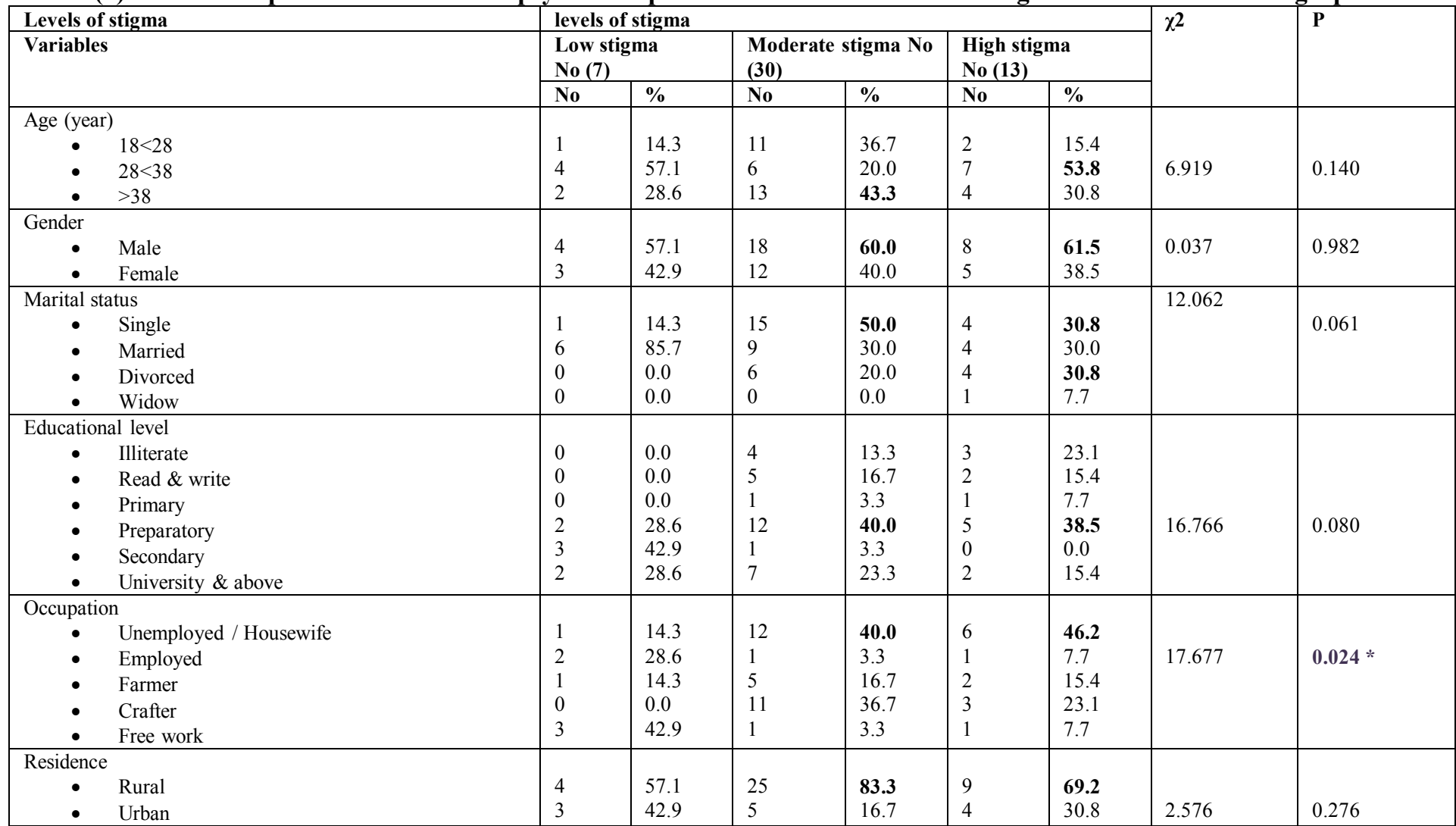

Table (5): shows that, there were no statistically significant differences between internalized stigma levels and all sociodemographic data of the patients except regarding occupation at ( $p$-value $=0.024)$. 
Minia Scientific Nursing Journal (Print - ISSN 2537-012X) (Online - ISSN 2785-9797) Vol. (9) No. (1) June 2021

Table (6): Relationship between the studied psychiatric patients' levels of internalized stigma and their clinical data.

\begin{tabular}{|c|c|c|c|c|c|c|c|c|}
\hline \multirow{3}{*}{$\begin{array}{l}\text { Levels of stigma } \\
\text { Variables }\end{array}$} & \multicolumn{6}{|c|}{ levels of stigma } & \multirow[t]{3}{*}{$\chi^{2}$} & \multirow[t]{3}{*}{$\mathrm{P}$} \\
\hline & \multicolumn{2}{|c|}{$\begin{array}{l}\text { Low stigma } \\
\text { No }(7)\end{array}$} & \multicolumn{2}{|c|}{$\begin{array}{l}\text { Moderate stigma No } \\
(30)\end{array}$} & \multicolumn{2}{|c|}{$\begin{array}{l}\text { High stigma } \\
\text { No (13) }\end{array}$} & & \\
\hline & No & $\%$ & No & $\%$ & No & $\%$ & & \\
\hline $\begin{array}{cl}\text { Diagnosis } & \\
\text { - } & \text { Bipolar } \\
\text { - } & \text { Boarderline personality } \\
\text { - } & \text { Depression } \\
\text { - } & \text { Obsessive compulsive(OCD) } \\
\text { - } & \text { Schizoaffective } \\
\text { - } & \text { Schizophrenia }\end{array}$ & $\begin{array}{l}1 \\
0 \\
0 \\
1 \\
2 \\
3\end{array}$ & $\begin{array}{l}14.3 \\
0.0 \\
0.0 \\
14.3 \\
28.6 \\
42.9\end{array}$ & $\begin{array}{l}8 \\
1 \\
5 \\
1 \\
6 \\
9\end{array}$ & $\begin{array}{l}26.7 \\
3.3 \\
16.7 \\
3.3 \\
20.0 \\
30.0\end{array}$ & $\begin{array}{l}4 \\
1 \\
1 \\
0 \\
4 \\
3\end{array}$ & $\begin{array}{l}\mathbf{3 0 . 8} \\
7.7 \\
7.7 \\
0.0 \\
\mathbf{3 0 . 8} \\
23.1\end{array}$ & 6.338 & 0.786 \\
\hline $\begin{array}{l}\text { Disease duration } \\
\text { - Less than one year } \\
\text { - } \quad \text { From } 1 \text { year to } 3 \text { years } \\
\text { - } \quad \text { From } 3 \text { years to } 5 \text { years } \\
\text { - } \quad \text { More than } 5 \text { years }\end{array}$ & $\begin{array}{l}1 \\
2 \\
2 \\
2\end{array}$ & $\begin{array}{l}14.3 \\
28.6 \\
28.6 \\
28.6\end{array}$ & $\begin{array}{l}5 \\
5 \\
2 \\
18\end{array}$ & $\begin{array}{l}16.7 \\
16.7 \\
6.7 \\
\mathbf{6 0 . 0}\end{array}$ & $\begin{array}{l}1 \\
4 \\
0 \\
8\end{array}$ & $\begin{array}{l}7.7 \\
30.8 \\
0.0 \\
61.5\end{array}$ & 7.409 & 0.285 \\
\hline $\begin{array}{c}\text { Duration of hospitalization } \\
\bullet \quad \text { Less than } 1 \text { month } \\
\text { - From } 1 \text { to } 2 \text { months } \\
\text { - } \quad \text { From } 2 \text { t o3 months }\end{array}$ & $\begin{array}{l}3 \\
4 \\
0\end{array}$ & $\begin{array}{l}42.9 \\
57.1 \\
0.0\end{array}$ & $\begin{array}{l}23 \\
7 \\
0\end{array}$ & $\begin{array}{l}76.7 \\
23.3 \\
0.0\end{array}$ & $\begin{array}{l}12 \\
0 \\
1\end{array}$ & $\begin{array}{l}92.3 \\
0.0 \\
7.7\end{array}$ & 11.128 & 0.025 * \\
\hline $\begin{array}{cl}\text { Frequency } & \text { of hospitalization } \\
- & \text { None } \\
\text { - } & \text { Once } \\
\text { - } & \text { Twice } \\
\text { - } & \text { Three times } \\
\text { - } & \text { More than } 3 \text { times }\end{array}$ & $\begin{array}{l}2 \\
1 \\
1 \\
1 \\
2\end{array}$ & $\begin{array}{l}28.6 \\
14.3 \\
14.3 \\
14.3 \\
28.6\end{array}$ & $\begin{array}{l}12 \\
3 \\
1 \\
6 \\
8\end{array}$ & $\begin{array}{l}\mathbf{4 0 . 0} \\
10.0 \\
3.3 \\
20.0 \\
26.7\end{array}$ & $\begin{array}{l}3 \\
3 \\
1 \\
1 \\
5\end{array}$ & $\begin{array}{l}23.1 \\
23.1 \\
7.7 \\
7.7 \\
\mathbf{3 8 . 5}\end{array}$ & 4.461 & 0.813 \\
\hline $\begin{array}{cc}\text { type of admission } \\
\bullet \quad \text { Voluntary } \\
\bullet \quad \text { Involuntary }\end{array}$ & $\begin{array}{l}5 \\
2\end{array}$ & $\begin{array}{l}71.4 \\
28.6\end{array}$ & $\begin{array}{l}18 \\
12\end{array}$ & $\begin{array}{l}\mathbf{6 0 . 0} \\
40.0\end{array}$ & $\begin{array}{l}8 \\
5\end{array}$ & $\begin{array}{l}\mathbf{6 1 . 5} \\
38.5\end{array}$ & 0.316 & 0.854 \\
\hline
\end{tabular}

Table (6): clarifies relationship between the studied psychiatric patients' levels of internalized stigma and their clinical data. It was found that, there were no statistically significant differences between internalized stigma levels and all clinical data of the patients except regarding duration of patients' hospitalization $(p$-value $=0.025)$.

\section{Discussion}

The present study revealed that more than half of the studied psychiatric patients were males, this may be explained by that the number of female rooms and beds were less than those of males, where there were three rooms with two beds only for each one for females' section from the total capacity of the hospital. This result is like Kaşli \& Bademli (2020) who found that more than half of the studied patients were males. In contrast, Chang \& Chen (2020) found that the majority of the Chinese participants were females. This contradiction in the previous study with the current may be due to the cultural differences and different attitudes of various societies regarding mental illness.

As regards to clinical data of the studied patients, the current study illustrated that, less than one third of them had schizophrenia and more than half had the disease for more than three years. This could be related to that schizophrenia is the most popular chronic psychiatric diagnosis in the world; this finding is supported by the study conducted by Omer et al., (2016) in Minia, Upper Egypt who reported that more than half of the studied patients had schizophrenia with the mean duration of the disease $5.2+4.8$ years.

Regarding to the studied patients' responses to ISMS, the current study revealed that, in alienation subscale, more than half of the studied patients were strongly agree that "they were disappointed for having a mental illness", and "having mental illness has spoiled their lives". On stereotype endorsement subscale, there were more than one third of the patients were strongly agree that "mentally ill people tend to be violent". As regard to discrimination experience subscale, the current study pointed to there were more than half of the patients were strongly agreeing that "people ignore them and treat them less seriously". In addition, on social withdrawal subscale, there were more than half of them were strongly

$P$ a g e | 132 agree that "negative stereotypes about mental illness keep them isolated from the world". This finding could be understood because of the patients' negative feelings and under appreciation toward themselves, misunderstandings of the nature of mental illness and lack of social reassurance as well as social support.

These findings agree to somewhat with Omer et al., (2016) who reported that, in alienation subscale, less than half of the studied patients agreed that "people without mental illness couldn't possibly understand them", and more than one third agreed that "having a mental illness has spoiled their lives" and "they became inferior to others who don't have mental illness". In stereotype endorsement subscale, less than half of the studied patients agreed that "mentally ill people tend to be violent". As regard to discrimination experience subscale, more than half of the studied patients agreed that "others think that they can't achieve much in life because they have a mental illness", while less than half of them agreed that "people ignore them or take them less seriously just because they have a mental illness". In social withdrawal subscale, about half of the studied patients agreed that "they didn't talk about themselves much because they didn't want to burden others with their mental illness".

However, these findings are contradicting with the study of Leep, (2015) who found that, the highest means of internalized stigma items were in the phrases: "I feel out of place in the world because I have a mental illness", "People ignore me or take me less seriously just because I have a mental illness", "People often patronize me or treat me like a child just because I have a mental illness" and "Being around people who don't have a mental illness makes me feel out of place or inadequate".

In relation to the stigma resistance subscale, the current study revealed that, more than half of the patients were 
strongly disagree that "People with mental illness make important contributions to society". This could be explained from two sides, firstly, the society culture and their points of view about the psychiatric disorders and its patients who are not competent to share any community responsibility as people consider them "made". Secondly, the patients' negative views about themselves which might be attained from the surroundings that make them feel incompetent enough to gain any achievement. Moreover, those patients said "no one accepts to engage a psychiatric patient in any job and the symptoms interfere with any achievement". Also, they avoid the anticipated rejection.

This finding is similar to Omer et al., (2016) whose results revealed that, about half of them were disagreed that, people with mental illness make important contributions to society. However, the current study also postulated that, more than half of the patients were strongly disagree that "In general, they were able to live their lives the way they want to", there were also more than half were strongly agree that "they feel comfortable being seen in public with an obviously mentally ill person". This could be related to the negative general view of the society to them that made them feel in adequate or nonproductive and unable to add to the community in which they live.

These findings are contradicted with James, 2013 who found that, on the stigma resistance domain, more than three-fourths of participants were agree or strongly agree on items of "I can have a good, fulfilling life, despite my mental illness" and "people with mental illness make important contributions to society". This contradiction may be explained by the community cultural differences. Also, Omer et al., (2016) found that, more than half of the patients were agree that "they can have a good fulfilling life, despite their mental illness" and about half were agree that "in general, they were able to live the life the way they want to". This contradiction might be because of the sample size and the patients' differences.

When comparing the sub-domains of the used internalized stigma of mental illness scale, it was observed that, the highest mean score was related to "stereotype endorsement" and "social withdrawal" domain followed by "alienation" domains, respectively. This might be explained that it is frequently encountered in Egypt and in Arab as general that psychiatric patients are labeled as aggressive, dangerous, out of control and are possessed by the devil. These traditional judgments and beliefs about these disorders might lead patients to endorse stereotypes. In another way, those studied psychiatric patients were not have the complete courage to face their surrounding people with their illness, because their feelings of disappointment and sense of inferiority which emphasize the concept of the stigma internalization that in turn isolated them from the others and made them experience the stereotypes of the illness.

This result agrees with the study of Kaşli \& Bademli., (2020) who reported that the highest means of the internalized stigma sub-domains observed were in "stereotype endorsement" and "social withdrawal" domains respectively followed by "alienation" domain. Furthermore, some studies conducted among patients with schizophrenia in Turkey by Yılmaz \& Kavak., (2020) and Karakaş et al., 2016 reported that the most affected subscale was stereotype endorsement and explained this by that the traditional Turkish values and beliefs support the view that mental illness is a punishment for faults and being a person with mental illness is perceived as a shame.

The current study showed that, most of the studied patients had moderate to high level of internalized stigma. This might be explained by a lack of awareness among psychiatric patients as well as their families and surroundings about the nature of psychiatric disorders which result in public stigma and in turn cause internalized stigma among those patients. Moreover, the social media play an observable role in drawing the picture of the mentally ill patients in people eyes and in the society, as the majority if not all of produced films present the psychiatric patient as an aggressive, mad and forsaken.

This result is in conjunction with the study of Young \& Ng., (2016) who revealed that, more than one third of patients with mental illness were having high level of internalized stigma. Also, Yildirim \& Kavak-Budak., (2020) found that the studied patients had high internalized stigma level. Furthermore, this result agrees with Bukhari et al., (2019) who also found that the patients had high level of internalized stigma. However; this finding is contradicted with the result obtained from Szcześniak et al., (2018) which indicated that the internalized stigma mean level of the studied patients was $2.23 \pm 0.5$ that indicates mild level of internalized stigma. This might be due to the cultural differences.

The current study revealed no statistically significant differences as regarding to sociodemographic data and internalized stigma except for the patients' occupation. This could be explained by that when the psychiatric patients go to their works they exposed to discrimination and biases because of the disorder stigma. This result is similar to the result of Holubova et al., (2016) who illustrated that self-stigma was associated significantly with employment. Meanwhile, this current finding is coincided partially with the study of Paraskevoulakou et al., (2017) who reported no statistically significant relationship have been found as regarding to age and gender. Accordingly, Sadeghian et al., (2019) explored no statistically significant differences among the study and control groups in terms of gender, marital status, educational level and levels of internalized stigma. While this result is contradicted to those who suggested virtually that, the whole of the socio-demographic variables were not related to the internalized stigma (Young \& Ng., 2016).

According to the clinical data, the findings of the present study revealed that, there were no statistically significant differences between the total levels of internalized stigma and clinical data of the patients except for their duration of hospitalization. This could be explained by that the hospitalization itself might be considered a stigma according to patients and society. Within the context of these results, Sadeghian et al., (2019) reported in their study that, there wereonly three variables only that were significantly differ including having another physical illness, suicidal attempts numbers and duration of hospitalization. However, in the study of Holubova et al., (2016), it was presented that there were no statistically significant differences in the level of internalized stigma and all clinical data of the patients.

\section{Conclusion}

Results of the current study concluded that most of the studied psychiatric patients were having moderate to severe level of the internalized stigma. Moreover, there were no statistically significant differences between internalized stigma levels and all sociodemographic as well as clinical data 
of the patients except for occupation and duration of patients hospitalization.

\section{Recommendations}

- Design and implement psycho-educational programs to decrease internalized stigma.

\section{References}

(1) American Psychiatric Association (2013). Diagnostic and Statistical Manual of Mental Disorders, 5th Edn. Washington, DC: American Psychiatric Association. [Google Scholar].

(2) Berry, C., \& Greenwood, K. (2018). Direct and indirect associations between dysfunctional attitudes, self-stigma, hopefulness and social inclusion in young people experiencing psychosis. Schizophrenia research, 193, 197-203.

(3) Bukhari, S. R., Imtiaz, A., Akbar, N., Malik, U. A., \& Gilani, A. (2019). Internalized Stigma, Quality of Life and Self Esteem in Chronic Schizophrenic Patients. Pakistan Journal of Medical Research, 58(1), 13.

(4) Chang, C., \& Chen, F. (2020). Relationships of Family Emotional Support and Negative Family Interactions with the Quality of Life among Chinese People with Mental Illness and the Mediating Effect of Internalized Stigma. Psychiatric Quarterly, 1-13.

(5) Charlson F, van Ommeren M, Flaxman A, Cornett J, Whiteford H, Saxena S. (2019). New WHO prevalence estimates of mental disorders in conflict settings: a systematic review and metaanalysis. Lancet; 394(10194):240-8.

(6) Corrigan, P., \& Rao, D. (2012). On the self-stigma of mental illness: stages, disclosure, and strategies for change. Canadian journal of psychiatry. Revue canadienne de psychiatrie, 57(8), 464-469. https://doi.org/10.1177/070674371205700804.

(7) Drapalski, A., Lucksted, A., Perrin, P., Aakre, J., Brown, C., DeForge, B., \& Boyd, J. (2013). A model of internalized stigma and its effects on people with mental illness. Psychiatric Services, 64(3), 264-269.

(8) Ebrahim, O, Al-Attar, G.S.T., Gabra, R. (2020). Stigma and burden of mental illness and their correlates among family caregivers of mentally ill patients. J. Egypt. Public. Health. Assoc. 95, 31. https://doi.org/10.1186/s42506-020-00059-6.

(9) Eksteen, H., Becker, P., \& Lippi, G. (2017). Stigmatization towards the mentally ill: Perceptions of psychiatrists, pre-clinical and post-clinical rotation medical students. International Journal of Social Psychiatry, 63(8), 782-791.

(10) Hofer, A., Mizuno, Y., Frajo-Apor, B., Kemmler, G., Suzuki, T., Pardeller, S., \& Uchida, H. (2016). Resilience, internalized stigma, self-esteem, and hopelessness among people with schizophrenia: Cultural comparison in Austria and Japan. Schizophrenia research, 171(1-3), 86-91.

(11) Hofer, A., Post, F., Pardeller, S., Frajo-Apor, B., Hoertnagl, C., Kemmler, G., \& Fleischhacker, W. (2019). Self-stigma versus stigma resistance in schizophrenia: Associations with resilience, premorbid adjustment, and clinical symptoms. Psychiatry research, 271, 396-401.

(12) Holubova, M., Prasko, J., Latalova, K., Ociskova, M., Grambal, A., Kamaradova, D., ... \& Hruby, R. (2016). Are self-stigma, quality of life, and clinical data interrelated in schizophrenia spectrum patients? A cross-sectional outpatient study. Patient preference and adherence, 10, 265.

(13) Howland, M., Levin, J., Blixen, C., Tatsuoka, C., \& Sajatovic, M. (2016). Mixed-methods analysis of internalized stigma correlates in poorly adherent individuals with bipolar disorder. Comprehensive psychiatry, 70, 174-180. https://doi.org/10.1016/j.comppsych.2016.07.012

(14) Kamaradova, D., Latalova, K., Prasko, J., Kubinek, R., Vrbova, K., Mainerova, B., \& Tichackova, A. (2016). Connection between self-stigma, adherence to treatment, and discontinuation of medication. Patient preference and adherence, 10, 1289.

(15) Karakaș, S. A., Okanll, A., Yılmaz, E. (2016). The effect of internalized stigma on the self-esteem in patients with schizophrenia. Archives of Psychiatric Nursing, 30, 648-652.
(16) Kaşli, S., Al, O., \& Bademli, K. (2020). Internalized stigmatization and subjective recovery in individuals with chronic mental illness. International Journal of Social Psychiatry, 0020764020960762.

(17) Leep, K. M. (2015). Stigma reduction initiative to increase community integration for those living with a persistent mental illness (Doctoral dissertation, Capella University).

(18) Lien, Y., Chang, H., Kao, Y., Tzeng, N., Lu, C., \& Loh, C. (2018) Insight, self-stigma and psychosocial outcomes in Schizophrenia: A structural equation modelling approach. Epidemiology and Psychiatric Sciences, 27(2), 176-185. doi:10.1017/S2045796016000950

(19) Olçun, Z., Altun, Ö. (2017). The correlation between schizophrenic patients' level of internalized stigma and their level of hope. Archives of Psychiatric Nursing, 31, 332-337.

(20) Omer, A., Kader, N., \& Sayed, N. (2016). Insight and its relationship with internalized stigma among psychiatric patients. IOSR Journal of Nursing and Health Sciences, 5(2), 1121

(21) Paraskevoulakou, A., Vrettou, K., Pikouli, K., Triantafillou, E., Lykou, A., \& Economou, M. (2017). Mental illness related internalized stigma: Psychometric Properties of the Brief ISMI Scale in Greece. Materia Socio-medica, 29(3), 211.

(22) Picco L, Pang S, and Lau YW, (2016). Internalized stigma among psychiatric outpatients: associations with quality of life, functioning, hope and self-esteem. Psychiatry Res; 246:500-506.

(23) Ritsher, J., Otilingam, P., Grajales, M. (2003). Internalized stigma of mental illness: Psychometric properties of a new measure. Psychiatry Research, 121, 31-49.

(24) Sadeghian, E., Rostami, P., Shamsaei, F., \& Tapak, L. (2019). The effect of counseling on stigma in psychiatric patients receiving electroconvulsive therapy: A clinical trial study. Neuropsychiatric Disease and Treatment, 15, 3419.

(25) Schwarzbold, M., Kern, R., Novacek, D., McGovern, J., Catalano, L., \& Green, M. (2021). Self-stigma in psychotic disorders: Clinical, cognitive, and functional correlates in a diverse sample. Schizophrenia Research, 228, 145-150.

(26) Steel Z, Marnane C, Iranpour C, Chey T, Jackson JW, Patel V, et al. (2014). The global prevalence of common mental disorders: a systematic review and meta-analysis 1980-2013. Int J Epidemiol; 43(2):476-93.

(27) Szcześniak, D., Kobyłko, A., Wojciechowska, I., Kłapciński, M., \& Rymaszewska, J. (2018). Internalized stigma and its correlates among patients with severe mental illness. Neuropsychiatric disease and treatment, 14, 2599-2608. https://doi.org/10.2147/NDT.S169051.

(28) Tesfaye, E., Worku, B., Girma, E., \& Agenagnew, L. (2020). Internalized stigma among patients with mood disorders in Ethiopia: a cross-sectional facility-based study. International journal of mental health systems, 14, 1-10.

(29) Vrbova K, Prasko J, Holubova M, et al. (2016). Self-stigma and schizophrenia: a cross-sectional study. Neuropsychiatr Dis Treat.;12:3011-3020. [PMC free article] [PubMed] [Google Scholar]

(30) Yildirim, T., \& Kavak Budak, F. (2020). The relationship between internalized stigma and loneliness in patients with schizophrenia. Perspectives in Psychiatric Care, 56(1), 168-174.

(31) Yılmaz, E., \& Kavak, F. (2020). Effects of mindfulness-based psychoeducation on the internalized stigmatization level of patients with schizophrenia. Clinical nursing research, 29(7), 496503.

(32) Yılmaz, E., \& Okanlı, A. (2015). The effect of internalized stigma on the adherence to treatment in patients with schizophrenia. Archives of Psychiatric Nursing, 29(5), 297-301.

(33) Young DK, Ng PY. (2016). The prevalence and predictors of selfstigma of individuals with mental health illness in two Chinese cities. Int J Soc Psychiatry.;62(2):176-85. https://doi.org/10.1177/0020764015614596 